Saray Mormeneo Bayo ${ }^{1}$

María Pilar Palacián Ruiz

Rosa María Martínez

Álvarez ${ }^{2}$

Concha López Gómez'

Silvia Loscos Aranda ${ }^{2}$

María Cruz Villuendas Usón ${ }^{1}$

\title{
Candida bracarensis, an emerging yeast involved in human infections
}

${ }^{1}$ Servicio de Microbiología. Hospital Universitario Miguel Servet. Zaragoza. España

${ }^{2}$ Servicio de Enfermedades Infecciosas. Hospital Universitario Miguel Servet. Zaragoza. España

Article history

Received: 24 January 2021; Revision Requested: 18 February 2021; Revision Received: 21 April 2021; Accepted: 7 May 2021; Published: 5 July 2021

\section{Sir,}

Invasive candidiasis is an increasingly detected complication in hospitalized adult patients, due to an increase in patients at risk (patients admitted to intensive care units, post-surgical patients, neutropenic and immunosuppressed patients). Non- albicans Candida species have increased in multiple centers and new species are proposed. This is the case of Candida nivariensis and Candida bracarensis that are phylogenetically related with C. glabrata, although with sufficiently genotypically different to justify their assignment as separate species [1].

Since $C$. bracarensis was described, the number of cases has been low. We added our own case and experience with this type of infection. A 67-year-old male, with a history of psoriasis with arthropathy in treatment with methotrexate, underwent surgery in October 2018 to place a branch endoprosthesis in abdominal aorta, with celiac trunk, superior mesenteric and renal arteries stents. In the next 24 hours after surgery, he was reoperated for massive ischemia of the small intestine with preservation of the onset of jejunum.

During admission to the ICU in the postoperative period, he had fever maintained with increasing leucocytosis without elevation of procaltitonin and no changes in abdominal examination. Blood cultures were negative. The patient was empirical treated with linezolid and fluconazole. Forty-eight hours later, the patient presented pain, oedema and signs of infection of the left arm where peripheral central access catheter (PICC) was inserted the day of the surgery. Catheter was removed and new blood cultures were sent. A yeast was isolated in blood cultures at five days so the incubation of the other pair of blood cultures extracted the same day was prolonged, with growth on the sixth day. In the semi-quantitative culture of the catheter (Maki technique), more than 100 CFUs grew at

Correspondence:

Saray Mormeneo Bayo

Servicio de Microbiologia. Hospital Universitario Miguel Servet. Zaragoza. España E-mail: samorbayo@hotmail.com
48 hours, which were identified by mass spectrometry (MALDI-TOF Bruker ${ }^{\circledR}$, being C. bracarensis with a score 2.17 and 1.97 in blood cultures and catheter respectively. Subsequently sequencing of the ITS regions of the DNA was performed, obtaining the same identification.

Antifungal susceptibility was performed using Sensititre Yeast One ${ }^{\circledR}$. In our case, interpretations of MICs in terms of susceptibility were performed according to the criteria of Clinical and Laboratory Standards Institute [2]. The MICs were: 4 $\mathrm{mg} / \mathrm{L}$ for fluconazole, $0.5 \mathrm{mg} / \mathrm{L}$ for posaconazole, $0.125 \mathrm{mg} / \mathrm{L}$ for voriconazole, $\leq 0.015 \mathrm{mg} / \mathrm{L}$ for anidulafungin, $0.015 \mathrm{mg} / \mathrm{L}$ for micafungin, $0.03 \mathrm{mg} / \mathrm{L}$ for caspofungin, $0.125 \mathrm{mg} / \mathrm{L}$ for 5-fluorocytosine and $0.5 \mathrm{mg} / \mathrm{L}$ for amphotericin B.

Taking into account the microbiology report, the dose of fluconazole was increased to $800 \mathrm{mg}$ intravenous due to the big resection of the small intestine and digestive tract tolerance. Treatment was maintained for 14 days after negative blood cultures with good clinical evolution, complete resolution of the phlebitis and discarding ocular involvement.

In our knowledge, $C$. bracarensis has been isolated in blood cultures from four patients [1,3-5], two of them with haematological disease [1,5]. In the case of Lockhart et al. [4], they were first identified as C. glabrata as Correia et al. also described [3].

The susceptibility profile of $C$. bracarensis was similar to $C$. glabrata with reduced susceptibility to fluconazole. However, Bishop et al. [6] describe the case of $C$. bracarensis resistant to all triazoles tested (fluconazole, itraconazole, voriconazole and posaconazole) recovered from the throat of an oncology patient. This patient had a longest hospital stay and he had received prior amphotericin, voriconazole and caspofungin treatment.

In relation to the outcome of the patients in whom C. bracarensis was isolated in blood culture, allusion is made only in the article of Warren et al. [5]. The patient was treated with a 2-week course of caspofungin. Subsequent blood cultures performed while the patient was on caspofungin therapy were 
negative. However, the patient dead due to his underlying disease.

To date, C. bracarensis has been collected from various body locations, as well as other Candida species, but especially from mucosal surfaces, and is clearly associated with infection and colonization [1,3-6].

A correct identification of the species of the genus Candida may have important implications for the treatment of invasive candidiasis. The current prevalence of $C$. bracarensis has been based on the reidentification of $C$. glabrata isolates $[1,3,4]$. Fortunately, species identification methods have evolved, as in our case where identification was possible due to MALDI-TOF

In the same way, it will be important to determine the susceptibility to antifungal therapies. It has been described that its susceptibility profile is similar to that of $C$. glabrata $[1,4-7]$, as in our case, where the patient evolved favourably with fluconazole. However, resistance to all azoles has been described [6].

This report supports the pathogenic role of $C$. bracarensis and the importance of having molecular techniques for proper identification. In addition, the study of the antifungal susceptibility is necessary, given the lack of data in the literature.

\section{FUNDING}

None to declare

\section{CONFLICTS OF INTEREST}

The authors declare that they have no conflicts of interest.

\section{REFERENCES}

1. Cuenca-Estrella M, Gomez-Lopez A, Isla G, Rodriguez D, Almirante $B$, Pahissa A et al; Barcelona Candidemia Project Study Group. Prevalence of Candida bracarensis and Candida nivariensis in a Spanish collection of yeasts: comparison of results from a reference centre and from a population-based surveillance study of candidemia. Med Mycol. 2011;49(5):525-9. doi: 10.3109/13693786.2010.546373.

2. Clinical and Laboratory Standards Institute. Epidemiological Cuttoff Values for Antifungal Susceptibility Testing. 2nd ed. CLSI supplement M59. Wayne, PA: The Institute; 2018

3. Correia A, Sampaio $P$, James $S$, Pais C. Candida bracarensis sp. nov., a novel anamorphic yeast species phenotypically similar to Candida glabrata. Int J Syst Evol Microbiol. 2006;56(Pt 1):313-7. doi: 10.1099/ijs.0.64076-0.

4. Lockhart SR, Messer SA, Gherna M, Bishop JA, Merz WG, Pfaller MA et al. Identification of Candida nivariensis and Candida bracarensis in a large global collection of Candida glabrata isolates: comparison to the literature. J Clin Microbiol. 2009;47(4):1216-7. doi: 10.1128/JCM.02315-08.
5. Warren TA, McTaggart L, Richardson SE, Zhang SX. Candida bracarensis bloodstream infection in an immunocompromised patient. J Clin Microbiol. 2010;48(12):4677-9. doi: 10.1128/JCM.01447-10.

6. Bishop JA, Chase N, Magill SS, Kurtzman CP, Fiandaca MJ, Merz WG. Candida bracarensis detected among isolates of Candida glabrata by peptide nucleic acid fluorescence in situ hybridization: susceptibility data and documentation of presumed infection. J Clin Microbiol. 2008; 46(2):443-446. doi:10.1128/JCM.01986-07.

7. Treviño-Rangel RJ, Espinosa-Pérez JF, Villanueva-Lozano H, Montoya AM, Andrade A, Bonifaz A et al. First report of Candida bracarensis in Mexico: hydrolytic enzymes and antifungal susceptibility pattern. Folia Microbiol (Praha). 2018;63(4):517-523. doi: 10.1007| s12223-018-0592-5. 